\title{
Understanding the concept of Taguchi Technique Optimization of Material Surface Roughness and Removal Rate for metals in CNC Turning Operation: A Review
}

\author{
${ }^{* 1}$ Shailesh Kumar and ${ }^{2} \mathrm{Mr}$. Bharat Bhushan Vashist \\ ${ }^{1}$ M.Tech Research Scholar, Mechanical Engg. Deptt., Advanced Institute of Technology Management, Palwal (Faridabad) \\ 2 Assistant Professor, Mechanical Engg. Deptt., Advanced Institute of Technology Management, Palwal (Faridabad)
}

\begin{abstract}
The objective of present study is to reviews optimal setting of number of opportunities in research of influence of process parameters, tool geometry and cutting environment for different machining operations on metals and power consumption during turning of different kind of work material using various optimization techniques like Taguchi approach, genetic algorithm and RSM. Taguchi robust design technique using L., orthogonal array was used for experimental run reviews. ANOV $A$ is also used to find significance and percentage contribution of parameters for quality characteristics.
\end{abstract}

Keywords: ANOVA, orthogonal array, Response Surface Methodology, DOE

\section{Article Publication}

Published Online: 20-Jan-2022

*Author's Correspondence

8 Shailesh Kumar

8 M.Tech Research Scholar, Mechanical Engg. Deptt., Advanced Institute of Technology Management, Palwal (Faridabad)

\section{$\underline{10.31305 / \text { rrijm.2022.v07.i01.006 }}$}

$\triangle$ shaileshfaujdar061[at]gmail.com

(C) 2022 The Authors. Published by RESEARCH REVIEW International Journal of Multidisciplinary. This is an open access article under the CC BY-

NC-ND license

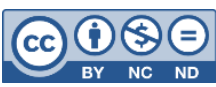

(https://creativecommons.org/licenses/ by-nc-nd/4.0/)

\section{Introduction}

In manufacturing sector reducing the cost of production without decreasing the quality of product is major concerns in order to sustain competition in the market. For producing the product, surface finish is the major requirements of the customer. Surface roughness influence by wear resistance, fatigue strength, corrosion resistance, coefficient of frication and dirt on the surface. W.H. Yang et al. (1998) The work piece for the experiment S45C steel and tungsten carbide tools were used. From the experimental study it was concluded that output response i.e., surface roughness and tool life can be improved. Puertas Arbizu et al. (2003) the parameter on turning process. Full factorial design technique combined with RSM was used to optimize the process parameter. C.H. Che-Haron et al. (2005) investigated the surface roughness of titanium alloy during rough turning operation. The cutting tool uncoated carbide was used under dry conditions. Three process parameters were taken for experimentation. Microstructure change was seen while machining with dull tool. Surface roughness value obtained less than $6 \mu \mathrm{m}$. Chih-Wei Chang et al. (2007) Study of NDYAG pulsed laser and three cutting parameters on surface roughness. $\mathrm{Al}_{2} \mathrm{O}$, work piece was selected for turning operation. Laser-assisted machining is used for higher MRR. Taguchi approach with L9 orthogonal array was used.

\section{Literature Survey}

A review of literature related to the field of optimization of process parameter during turning operation in different cutting environment. Since the study is mostly about parameter optimization for the material removal rate, surface roughness, power consumption and tool life using different type of optimization technique like Taguchi approach, RSM and genetic algorithm. This studied helps in the selection of the topic for my research work and various 
parameters associated and required for successfully performing turning operation. W.H. Yang et al. (1998) The work piece for the experiment S45C steel and tungsten carbide tools were used. From the experimental study it was concluded that output response i.e. surface roughness and tool life can be improved. Puertas Arbizu et al. (2003) the parameter on turning process. Full factorial design technique combined with RSM was used to optimize the process parameter. C.H. Che-Haron et al. (2005) investigated the surface roughness of titanium alloy during rough turning operation. The cutting tool uncoated carbide was used under dry conditions. Three process parameters were taken for experimentation. Microstructure change was seen while machining with dull tool. Surface roughness value obtained less than $6 \mu \mathrm{m}$. Chih-Wei Chang et al. (2007) Study of NDYAG pulsed laser and three cutting parameters on surface roughness. $\mathrm{Al}_{2} \mathrm{O}$, work piece was selected for turning operation. Laser-assisted machining is used for higher MRR. Taguchi approach with L9 orthogonal array was used. Ahmet Hascalik et al. (2008) This study used to determine optimal turning parameters for surface roughness and tool life. Ti.6AL.4V alloy was used as work piece. The cutting tool inserts CNMG 120408-883 was used. Based on ANOVA result concludes that feed rate plays important. H. Yanda et al. (2010) The cutting tool insert was used TiN coated carbide under dry condition. ANOVA is used to found \% contribution of output response. Experimental results for MRR compared with the results of FEM machining simulation deform-3D software. Nikolaos I. Galanis et al. (2010) Experiments performed on CNC lathe using coated carbide (TiN-Aloy-TiC) cutting tool. M. Kaladhar et al. (2011) Optimum machining parameters and significance of parameter were determined using ANOVA and F-test. M. kaladhar et al. (2012) Four diverse process parameters were taken at two diverse levels. MRR and surface roughness considered as an output. Ashok kumar sahoo et al (2012) studied effect of turning parameter on output responses like MRR and surface roughness. In this study Taguchi technique and GRA techniques were used to optimize of process parameter for turning of AISI 1040 steel. H.K. Dave et al (2012) the cutting parameter of diverse grade of EN material namely EN-8 and EN-31using different grade of cutting tool inserts. Optimum results were obtained by the use of Taguchi and ANONA techniques. From the experimental study it is conclude that depth of cut play significant role in MRR while inserts has maximum. S.K. et al. (2012) This study concludes that the optimum process parameter, according to maximum S/N ratio for the MRR feed. Md. Maksudul Islam et al. (2015) obtaining optimum process during turning of ASTM A48 Grey cast iron. L9 orthogonal array is used. HSS is used as a cutting tool. ANOVA was applied and material removal rate were studied. Optimum cutting parameters and significance of parameters were determined using ANOVA technique. Deveshpartap singh et al (2016) L9 orthogonal array is used. Minitab 15 was used for analysis. ANOVA was used to verify the result. ANOVA conclude that feed rate was the maximum contributed factor $54.65 \%$ to the surface roughness. Sujan Debnath et al. (2016) Mild steel was selected for turning operation and coated carbide insert is used for tool. The cutting flow condition LFHV was the most optimum cutting condition to reduce the tool wear and surface roughness. S. Sakthivelu et al. (2017) S. Sakthivelu et al. (2017) studied the in CNC turning of aluminum 6063 with tungsten carbide inserts effect of machining parameters on surface roughness and MRR. Three machining parameters have been adopted. Robust Taguchi technique design is used. An orthogonal L9 array was used. The mean response and contribution were calculated using the ANOVA method and signal-to-noise ratio.

\section{Literature Gap}

From the literature survey we can see that there are a number of opportunities in research of influence of process parameters, tool geometry and cutting environment for surface roughness; cutting forces; material removal rate: tool life, and power consumption during turning of different kind of work material using various optimization techniques like Taguchi approach, genetic algorithm and RSM. To reviews optimal setting of number of opportunities in research of influence of process parameters, tool geometry and cutting environment for different machining operations on metals and power consumption during turning of different kind of work material using various optimization techniques like Taguchi approach, genetic algorithm and RSM. Taguchi robust design technique using L., orthogonal array was used for experimental run reviews. ANOVA is also used to find significance and percentage contribution of parameters for quality characteristics. Also from the literature survey, it has been observed that there is limited research done which considers the influence of process parameter during $\mathrm{CNC}$ turning operation for EN-31 alloy steel using tungsten carbide cutting tool with rhombus geometry is not explored yet surface roughness and material removal rate. This material has high carbon percentage, hardness, compressive strength and wears resistance therefore used in wide range of applications like punches and dies, roller and ball bearing, gudgeon pins, and heavy gear and ejector pins. Hard turning (above $45 \mathrm{HRC}$ ) the temperature induce in the cutting zone is very high, excessive heat cause tool wear and hence reduce tool life. Analyze the three different processing parameters selected in this study and their effects on the initial response using the Taguchi method. By reviewing different paper studies of the experiment, robust design method using an orthogonal array was used. So the assortment of appropriate machining parameters to achieve the goals of the manufacturing industry is one of the major concerns. 


\section{Experimentation}

The proposal for present work is carried out by finding the gap in literature and future scope. Considerable experiments were performed on $\mathrm{CNC}$ turning machine to obtain the objectives by the suitable selection of materials, machining parameters and cutting tool inserts during turning process.

The experiments were conducted in the following sequence to attain the objectives

- Selection of materials.

- Selection of cutting factors and their levels.

- Selection of responses or quality characteristic.

- Selection of OA.

- Selection of cutting tool inserts.

- Preparation of set up for experiments.

- Calculation of material removal rate.

- Measurements of surface roughness.

\section{Selection of material}

The material selected for the work is EN-31 steel. The description of size of selected material is given as:

- Number of rods- three

- Diameter 48.3

- Length - $180 \mathrm{~mm}$

Three experiments are performed on a single rod in the form of step turning.

\section{Conclusion}

From the literature survey we can see that there are a number of opportunities in research of influence of process parameters, tool geometry and cutting environment for different machining operations on metals and power consumption during turning of different kind of work material using various optimization techniques like Taguchi approach, genetic algorithm and RSM. Analyze the three different processing parameters selected in this study and their effects on the initial response using the Taguchi method. By reviewing different paper studies of the experiment, robust design method using an orthogonal array was used. ANOVA is also used to find the significance and contribution of quality characteristic parameters.

\section{References}

Yang, W. P., \& Tarng, Y. S. (1998). Design optimization of cutting parameters for turning operations based on the Taguchi method. Journal of materials processing technology, 84(1). 122-129.

Arbizu, I. P., \& Perez, C. L. (2003). Surface roughness prediction by factorial design of experiments in turning processes. Journal of Materials Processing Technology, 143, 390-396.

Che-Haron, C. H., \& Jawaid, A. (2005). The effect of machining on surface integrity of titanium alloy Ti-6\% Al-4\% V. Journal of Materials Processing Technology, 166(2), 188192.

Chang, C. W., \& Kuo, C. P. (2007). Evaluation of surface roughness in laser-assisted machining of aluminum oxide ceramics with Taguchi method. International Journal of Machine Tools and Manufacture, 47(1), 141-147.

Hasçalık, A., \& Çaydaş, U. (2008). Optimization of turning parameters for surface roughness and tool life based on the Taguchi method. The International Journal of Advanced Manufacturing Technology, 38(9), 896-903.

Yanda, H., Ghani, J. A., Rodzi, M. N. A. M.. Othman, K., \& Haron, C. H. C. (2010). Optimization of gaterial removal rate, surface roughness and tool life on conventional dry turning of FCD700. International Journal of Mechanical and Materials Engineering, 5(2), 182-190.

Galanis, N. 1., \& Manolakos, D. E. (2010). Surface roughness prediction in turning of femoral head. The International Journal of Advanced Manufacturing Technology, 51(1), 7986.

Kaladhar, M., Subbaiah. K. V., Rao, C.. \& Rao, K. N. (2011), Application of Taguchi approach and Utility Concept in 
solving the Multi-objective Problem when turning AISI 202 Austenitic Stainless Steel. Journal of Engineering Science \& Technology Review, 4(1).

Sahoo, A. K., Baral, A. N., Rout, A. K., \& Routra, B. C. (2012). Multi-objective optimization and predictive modeling of surface roughness and material removal rate in turning using grey relational and regression analysis. Procedia Engineering, 38, 1606-1627.

Dave, H., Patel, L., \& Raval, H. (2012). Effect of machining conditions on MRR and surface roughness during CNC Turning of different Materials Using TiN Coated Cutting Tools-A Taguchi approach. International Journal Computations, 3(5), 925-930. of Industrial Engineering

Jha, S. K., Singh, S., \& Kumar, S. R. (2012). Experimental Analysis of CNC Turning using Taguchi Method. In Proceedings of Third International Conference on Advances in Mechanical Engineering, Delhi, India, DOI: 02. AETAME (Vol. 3, No. 15, pp. 91-95).

Kaladhar, M., Subbaiah, K. V., \& Rao, C. S. (2012). Determination of optimum process parameters during turning of AISI 304 Austenitic Stainless steels using Taguchi method and ANOVA. International Journal of lean thinking, 3(1), 1 19.

Islam, M. M., Hossain, S. S., \& Bhuyan, M. S. A. (2015). Optimization of Metal Removal Rate for ASTM A48 Grey Cast Iron in Turning Operation Using Taguchi Method. International Journal of Materials Science and Engineering, 3. 134-146.

Singh, D. P., \& Mall, R. N. (2015). Optimization of Surface Roughness of Aluminum by ANOVA based Taguchi Method using Minitab15 Software. International Journal For Technological Research In Engineering, 2(11), 2782-2787.

Debnath, S., Reddy, M. M., \& Yi, Q. S. (2016). Influence of cutting fluid conditions and cutting parameters on surface roughness and tool wear in turning process using Taguchi method. Measurement, 78, 111-119.

Sakthivelu, S., \& Prakash, R. S. (2017). Investigating the Effect of Machining Parameters in CNC Turning Using DOE Technique. Work, 2(02), 13-18. 